\title{
A Novel Technique of Using Sponge as Post-Operative Nasal Packing
}

\author{
Ike Thomas, ${ }^{1}$ Jathin Sam Thekkethil, ${ }^{1}$ Ramesh Chandra Kapoor, ${ }^{2}$ Tina Thomas, ${ }^{1}$ Pramod Thomas ${ }^{1}$
}

Introduction

$\underline{\text { ABSTRACT }}$

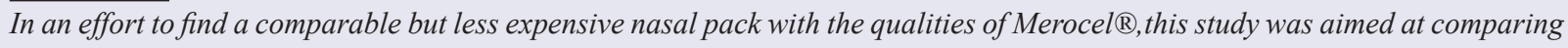
the clinical efficacy and patient comfort level, while simultaneously using Merocel ${ }^{\circledR}$ and commercially available sponge as packing material in the same patient.

\section{Materials and Methods}

This study included those patients who underwent septoplasty, turbinoplasty or FESS and nasal packing was done randomly

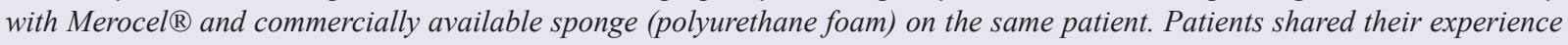
on the symptom questionnaire on the first post-operative day and they underwent sequential diagnostic nasal endoscopy to assess the endoscopic status of the nasal cavity, which were documented meticulously.

$\underline{\text { Result }}$

The post-operative bleeding control, pain during pack removal, general satisfaction, willingness to reuse and post-operative

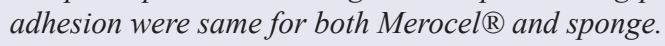

Conclusion

The innovative technique of using a commonly available, commercially prepared sponge which is as good as Merocel $\mathbb{R}$ is well supported due to its efficacy in hemostasis, less mucosal trauma and less pain during pack removal. So it may be used in developing countries where cost is a factor for compliance of patients for undergoing surgeries without compromising on quality. $\underline{\text { Kevwords }}$

Nasal Packing; Polyvinyl Alcohol; Polyurethanes

$\mathrm{N}$ asal Packing is one of the most common procedures done by Otorhinolaryngologists worldwide. It is often done after septoplasty and it aims at preventing postoperative bleeding, septal hematoma or nasal synechiae, ensuring mucoperichondrium flap to be in position and cartilage stabilization in order to get the best surgical results. ${ }^{1}$

It is done after Functional Endoscopic Sinus Surgery (FESS) to prevent postoperative bleeding. The ideal packs are easy to insert and remove without causing pain and discomfort. A wide variety of nasal packing materials are available in the market. Use of nasal packs vary in different countries. ${ }^{2}$ It may even vary in different places or institutions. Generally used nasal packing materials are antibiotic cream coated ribbon-gauze packs, custom made glove packs, Merocel ${ }^{\circledR}$ and the newer additions are Rapidrhino ${ }^{\circledR}$ and biodegradable nasal packs like Nasopore ${ }^{\circledR}$. Most of the patients feel pain, pressure and discomfort while packing and on removing the pack on the first post-operative day. ${ }^{3}$ Meroce $^{\circledR}{ }^{\circledR}$ is a foam type non- absorbable nasal packing material which is a cross-linked polyvinyl alcohol, which is commonly used nowadays. It is equally effective for haemostasis and less traumatic to the operated nasal mucosa, but it is expensive when compared with ribbon-gauze and glove packs.

Nowadays, there is an increasing trend of avoiding nasal packs for better patient comfort. Our effort is to find a comparable nasal pack which has the qualities of Merocel $^{\circledR}$ which is less expensive. Commercially produced Sponge (Polyurethane foam) is one such material, which is commonly available, less expensive and can be cut into specific sizes, autoclaved and used

1 - Believers Church Medical College Hospital,

Thiruvalla, Kerala

2 - Badr Al Samaa Hospital, Ruwi

Corresponding author:

Dr Jathin Sam Thekkethil

email: jathinsam@gmail.com 
as nasal pack. This study was aimed at comparing the clinical efficacy and patient comfort level, while simultaneously using Merocel $^{\circledR}$ and commercially available sponge as packing material in either nasal cavity in the same patient.

\section{Materials and Methods}

This prospective randomized clinical study was conducted from July 2009 to June 2014. The study protocol was approved by the institutional ethical committee. The authors asserts that all procedures contributing to this work comply with the ethical standards of the relevant national and institutional guidelines on human experimentation and with the Helsinki Declaration of 1975, as revised in 2008. The patients included in the study were counselled in detail regarding the use of two different nasal packs and their properties and a detailed informed consent was taken.

This study included patients age ranging from 17 years to 58 years, with chronic moderate to severe rhinosinusitis, septal deviations and turbinate hypertrophy who were planned for septoplasty surgery, turbinoplasty surgery or Functional Endoscopic Sinus Surgery (FESS) under general anaesthesia. The exclusion criteria for the study was revision FESS, patients with bleeding diathesis, patients on aspirin or anti-platelet drugs and hypertensive patients. Prior to the surgery, all patients underwent routine ENT examination and diagnostic nasal endoscopy. Computed tomography evaluation of paranasal sinuses were done for FESS and septoplasty patients. Patients were explained regarding the symptom questionnaire prior to their participation in the study. The patients included in the study were unaware of the type of nasal pack given in either nasal cavity.

The operating surgeon selected each side of the nose randomly for packing with Merocel $^{\circledR}$ or Sponge without any bias. The size of the Meroce $\mathrm{l}^{\mathbb{}}$ was standard (custom made to $4 \mathrm{~cm}$ along with a draw string used for removal) and the size of the commercially available sponge was cut and made into a size of $4 \mathrm{~cm}$ long, $1 \mathrm{~cm}$ breadth and $1.5 \mathrm{~cm}$ height, which was then autoclaved and used for nasal packing(Fig. 1).
All the patients were provided with oral antibiotics from the day of surgery for a period of one week and intranasal saline douches after pack removal from the first postoperative day. Patients shared their experience on the symptom questionnaire on the first postoperative day, after removal of the packs on both sides. The questionnaire was based on the standard Visual Analog Scale (VAS), wherein score score ' 0 ' meant no symptom and score ' 10 ' meant unbearable symptoms. The VAS questionnaire evaluated the various aspects of patient comfort with respect to pain and pressure during removal of pack, sleep disturbance and general satisfaction where the patients willingness to use the material in future for any other nasal surgeries.

The patients underwent sequential diagnostic nasal endoscopy on the 10th day and 30th day to assess the endoscopic status of the nasal cavity with regard to mucosal injury and healing status, adhesion, synechiae, infection and granulation. A grading scale from 0 to 3 was created for assessment of the severity of each of the above signs and for the assessment of bleeding in the immediate post-op, which were documented meticulously. The various proportions were compared using chi-square test statistic. The statistical analysis of was done by using the statistical software R.

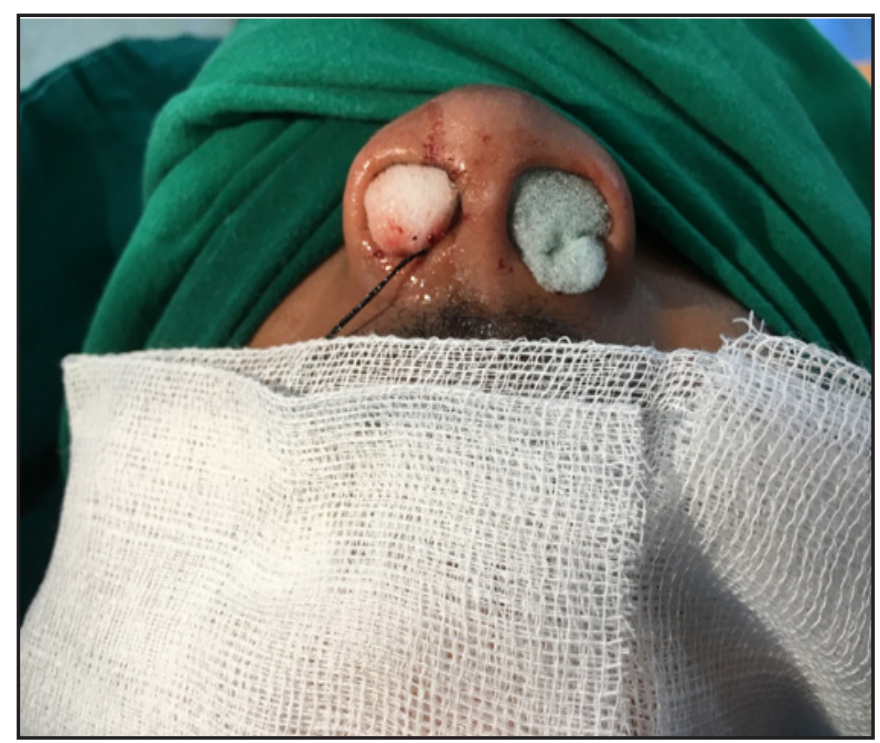

Fig. 1. Nasal packing with Merocel $^{\mathrm{R}}$ (with string attached to it) on one side and the other side packed with autoclaved sponge 


\section{Result}

In our study, a total of 50 patients were considered, out of which $5(10 \%)$ patients were less than 20 years of age, $36(72 \%)$ patients aged between 21 years to 40 years and $9(18 \%)$ patients above 40 years. In this, $31(62 \%)$ patients were males and $19(38 \%)$ patients were female. Out of these 50 patients, 21 (42\%) patients underwent septoplasty, 13 (26\%) patients had FESS and 16 (32\%) patients underwent turbinoplasty.

The first observation which was made during the study was regarding the hemostatic property or the bleeding control in the immediate postoperative period. The hemostatic property between the two materials in the immediate postoperative period was statistically similar. With regard to the hemostatic property, 41/50 patients $(82 \%)$ had excellent bleeding control on the sponge pack side with no bleeding and $3 / 50$ patients (6\%) had minimal bleeding, where there was minimal filling up of blood within the nasal cavity which did not flow out of the nostril and did not require repacking (TableI). $4 / 50$ patients $(8 \%)$ on sponge pack side had moderate bleeding, 2/50 patients (4\%) had severe bleeding and required repacking. The results on the sponge pack side were as comparable to the side with Merocel ${ }^{\circledR}$ pack, where $42 / 50$ patients $(84 \%)$ had excellent hemostsis with no bleeding and $4 / 50$ patients $(8 \%)$ had minimal bleeding, $3 / 50$ patients $(6 \%)$ with moderate bleeding and $1 / 50$ patients $(2 \%)$ had severe bleeding which required repacking. We did not face any

Table I: Grading of Postoperative bleeding control/Hemostasis

\begin{tabular}{|c|c|c|}
\hline \multicolumn{3}{|c|}{ control/Hemostasis } \\
\hline $\begin{array}{c}\text { BLEEDING } \\
\text { CONTROL }\end{array}$ & $\begin{array}{c}\text { MEROCEL } \\
(\mathbf{N}=50)\end{array}$ & $\begin{array}{c}\text { SPONGE } \\
(\mathbf{N}=50)\end{array}$ \\
\hline No bleeding & 42 & 41 \\
\hline $\begin{array}{c}\text { Minimal } \\
\text { bleeding }\end{array}$ & 4 & 3 \\
\hline $\begin{array}{c}\text { Moderate } \\
\text { bleeding }\end{array}$ & 3 & 4 \\
\hline $\begin{array}{c}\text { Severe } \\
\text { bleeding }\end{array}$ & 1 & 2 \\
\hline
\end{tabular}

secondary haemorrhage in any of the patients due to infections, on either side.

On analysing the data of the pain experienced by the patient during the time of pack removal, there was no statistical difference between the Merocel ${ }^{\circledR}$ side and the sponge side. On the Meroce ${ }^{\circledR}$ side, 27 (54\%) had no pain to mild pain and $23(46 \%)$ had moderate to severe pain (Table II). On the other hand, on the sponge side, $40(80 \%)$ had no pain to mild pain and $10(20 \%)$ had moderate to severe pain (Table II). Most notable finding is that 6 patients in the Merocel ${ }^{\circledR}$ side had severe pain while removing the nasal pack but none of the patients complained of severe pain on the sponge side, which may be due to the more rigid structure of the Merocel $^{\circledR}$ in comparison with the sponge.

On evaluation of the general satisfaction of the patients regarding reusing the packing material in the future for any nasal surgeries and for recommending any specific packing material for friends, relatives or for others, there was no statistical difference between Meroce $^{\circledR}$ and sponge group. On considering Merocel ${ }^{\circledR}$, $34(68 \%)$ patients were willing to reuse the material but $16(32 \%)$ patients were not willing to reuse. On considering sponge side, $46(92 \%)$ patients were willing to reuse sponge as packing material in future but $4(8 \%)$ patients were not willing to reuse (Table III).

In this evaluation, even though it is statistically not significant, one of the notable finding is that, out of the 16 patients who were not willing to reuse Merocel $^{\circledR}$ as packing material in future, $15(93.8 \%)$ are willing to

Table II: Grading of pain during removal of nasal pack

\begin{tabular}{|c|c|c|}
\hline $\begin{array}{c}\text { PAIN } \\
\text { DURING } \\
\text { REMOVAL }\end{array}$ & $\begin{array}{c}\text { MEROCEL }{ }^{\circledR} \\
(\mathbf{N}=50)\end{array}$ & $\begin{array}{c}\text { SPONGE } \\
(\mathbf{N}=50)\end{array}$ \\
\hline No pain & 1 & 4 \\
\hline Mild pain & 26 & 36 \\
\hline Moderate pain & 17 & 10 \\
\hline Severe pain & 6 & 0 \\
\hline
\end{tabular}


Table III: General Satisfaction of patients

\begin{tabular}{|c|c|c|}
\hline GENERAL & $\begin{array}{c}\text { MEROCEL }\left(\begin{array}{c}\text { SPONGE } \\
(\mathbf{N}=50)\end{array}\right. \\
(\mathbf{N}=50)\end{array}$ \\
\hline $\begin{array}{c}\text { Willingness to } \\
\text { reuse }\end{array}$ & 34 & 46 \\
\hline $\begin{array}{c}\text { Not willing to } \\
\text { reuse }\end{array}$ & 16 & 4 \\
\hline
\end{tabular}

$* \mathbf{p}=\mathbf{0 . 6 1 7}$

reuse sponge as packing material (Table IV).

On analysing the post-operativeadhesions and synechiaeafter 10 days of pack removal, no statistically significant difference seen $\left({ }^{*} \mathrm{p}=0.314\right)$.

On the Merocel® side, 35 (70\%) had no adhesions and $15(30 \%)$ had adhesions. On the sponge side, 39 (78\%) had no adhesions and 11 (22\%) had adhesions. All the adhesions in both groups were mild and easy to release and done as OPD procedure. No adhesions or synechiae seen on any side on the 30th day nasal endoscopy.

\section{Discussion}

Chronic rhinosinusitis (CRS), septal deviation, and inferior turbinate hypertrophy are among the most common diseases seen in the ENT department in current practice. These conditions are present in patients of all ages and both genders. Surgical procedures such as functional endoscopic sinus surgery (FESS), septoplasty and turbinoplasty, are often considered when medical treatments have failed. At the end of each of these procedures, nasal packs are placed into the nasal cavities to prevent bleeding of the wound.

Generally nasal packings include removable nasal packs like antibiotic cream coatedribbon-gauze packs, custom made glove pack,Merocel ${ }^{\circledR}$ etc. and recently introduced biodegradable nasal packing materials like Nasopore ${ }^{\mathrm{R}}$. FESS and other nasal surgeries are constantly evolving and it makes otorhinolaryngologists to create modifications in the nasal packs.

The innovations in nasal packing were motivated by the innate defects of conventional packing materials in quality of life during early postoperative period and the pain tolerated during nasal pack removal.

The postoperative treatment regimen of FESS is as important as the surgery itself, since the ultimate goal is to re-establish normal mucociliary clearance in the sinuses. So the nasal packs were expected to improve mucosal healing and avoid adhesion of mucosa in the nasal cavity. But, the foremost use of nasal pack is to control bleeding after sinus or septal surgery. Hence, many packing materials were time tested and proven, and some still being in the evaluation phase.

The use of removable nasal packs like antibiotic cream coated ribbon-gauze packs, glove packs and

Table IV: Comparison of General satisfaction of patients on using MerocelR and sponge as packing material

\begin{tabular}{|c|c|c|c|c|}
\hline & & \multicolumn{2}{|c|}{ SPONGE } & \multirow{2}{*}{ TOTAL } \\
\hline & & $\begin{array}{c}\text { WILLING TO } \\
\text { REUSE }\end{array}$ & $\begin{array}{l}\text { NOT WILLING TO } \\
\text { REUSE }\end{array}$ & \\
\hline \multirow{2}{*}{ Merocel ${ }^{\circledR}$} & Willing to Reuse & $\begin{array}{c}31 \\
-91.2 \%\end{array}$ & $\begin{array}{c}3 \\
-8.80 \%\end{array}$ & $\begin{array}{c}34 \\
-100 \%\end{array}$ \\
\hline & $\begin{array}{l}\text { Not Willing to } \\
\text { Reuse }\end{array}$ & $\begin{array}{c}15 \\
-93.8 \%\end{array}$ & $\begin{array}{c}1 \\
-6.3 \%\end{array}$ & $\begin{array}{c}16 \\
-100 \%\end{array}$ \\
\hline \multicolumn{2}{|c|}{ Total } & $\begin{array}{c}46 \\
-92 \%\end{array}$ & $\begin{array}{c}4 \\
-8 \%\end{array}$ & $\begin{array}{c}50 \\
-100 \%\end{array}$ \\
\hline
\end{tabular}

$* \mathbf{p}=\mathbf{0 . 6 1 7}$ 
Meroce ${ }^{\circledR}$ are widely used worldwide. The advantages for Meroce ${ }^{\circledR}$ nasal pack includes easy manipulation and alignment within the nasal cavity, and provide better supporting ability. ${ }^{4}$ But they have some disadvantages also. They are costlier than the ribbon- gauze pack or glove packs which are made in the hospital itself. ${ }^{5}$

Pain and pressure present when the pack is inside the nose and during removal are the common complaints of patients with Meroce ${ }^{\circledR}$ pack, which often decreases the quality of life of patients after nasal surgeries. ${ }^{1}$ Some patients have mentioned that the removal of packing material was the most painful experience in the whole of their life. ${ }^{6}$ Biodegradable nasal packs does not require the removal, as it gets absorbed inside the nose and thereby avoiding the pain during the pack removal. But, it increases the cost of nasal packs further. Hence, we developed the innovative idea of reducing the cost of nasal packs by using a material which is commonly available in the operation theatre and hospitals, and it is as good as other nasal packs.

Commercially produced Sponge (Polyurethane foam) is one such material. It is freely available in the operation theatre, which can be cut into specific sizes, autoclaved and used as packing material. Today's polyurethanes have been formulated to provide good biocompatibility, flexural endurance, high strength and high abrasion resistance. These attributes are important in supporting new applications of sponge by medical device manufacturers including artificial hearts, catheter tubing, feeding tubes, surgical drains, intra-aortic balloon pumps, dialysis devices, non-allergenic gloves, medical garments, hospital bedding, wound dressings and more.

Akita et al studied the benefits of polyurethane in split thickness skin graft donor wound healing, and they found out that the polyurethane dressing was superior to hydrogel in the wound healing time, amount of exudates, and frequency of dressing changes. ${ }^{7}$ Handel $\mathrm{N}$ et al studied the long term safety and efficacy of polyurethane foam covered breast implants and the result showed that the incidence of capsular contracture was dramatically lower with polyurethane foamcovered implants compared to smooth or mechanically textured implants; this beneficial effect persisted at least 10 years after implantation. ${ }^{8}$ These studies proved that the sponge can be used inside the body with long term durability without any complications. Long-term in vitro durability of polyurethane heart valves has been achieved and polyurethane valves manufactured from a commercially available textile polyurethane were capable of achieving more than 800 million cycles in laboratory fatigue testing (equivalent to more than 20 years of normal function). ${ }^{9}$

In our study, $46 \%$ patients had moderate to severe pain while removing the pack on the Merocel®side while only $20 \%$ patients had moderate to severe pain. Even though it is not statistically significant, the most notable finding is that, 6 patients in the Merocel ${ }^{\circledR}$ side had severe pain while removing the pack but none of the patients complained of severe pain on the sponge side, which may be due to the more rigid structure of the Merocel $\AA$ in comparison with the sponge. Many studies compared the pain during removal of various nasal packs with Merocel ${ }^{\circledR}$. Hesham et al reported that Rapidrhino ${ }^{\circledR}$ packs were less painful than Merocel ${ }^{\circledR}$ packs. ${ }^{10}$ In our study, pain during pack removal ofMeroce ${ }^{\circledR}$ and sponge are statistically similar.

Likewise, sponge had comparable hemostatic property and post-operative adhesion as that of the Merocel ${ }^{\circledR}$ in our study with no statistical difference between the two. Ragunandhan et al reported that $86.6 \%$ Merocel ${ }^{\circledR}$ pack patients provided excellent hemostasis with no bleeding. In our study, $84 \%$ Merocel $^{\mathbb{B}}$ pack and $82 \%$ sponge pack patient had excellent hemostasis with no bleeding. ${ }^{3}$ Hence, the hemostatic property of sponge was at par with Merocel $^{\mathbb{}}$. Yilmaz et al stated that adhesion developed in 7 (28\%) patients in the Merocel $^{\mathbb{R}}$ group in the 4-week follow-up. ${ }^{11}$ In our study it was $30 \%$ and all the adhesion were mild and easy to release and did not proceed to become a synechiae.

While considering the general satisfaction of patients in reusing the packing material in future $68 \%$ patients were willing to reuse Merocel ${ }^{\circledR}$ and $92 \%$ patients were willing to reuse sponge. Out of total number of patients who are not willing to reuse Merocel ${ }^{\mathbb{}}$ in future, 93.8\% patients are willing to reuse sponge instead of Meroce ${ }^{\circledR}$. Raghunandhan et al reported that the general satisfaction and willingness to reuse Nasopore ${ }^{R}$ was significantly high on comparison with Merocel $^{\circledR}{ }^{\circledR}{ }^{3}$ In our study, the general willingness to reuse sponge as 
a packing material is at par with Meroce $^{\circledR}$ and many patients prefer to use sponge instead of Merocel $^{\circledR}$, which is in accordance with the above quoted study. Hence, sponge is comparable to Merocel $^{\circledR}$.

\section{Conclusion}

Meroce ${ }^{\circledR}$ is a novel packing material which is used by most ENT surgeons after nasal surgeries due to its clinical efficiency in hemostasis and less trauma to nasal mucosa comparing to ribbon-gauze packing, but the disadvantages are the cost of Merocel ${ }^{\circledR}$ and the pain during removal of pack.

Even though 'no-packing technique' is there, but many ENT surgeons are not practicing it and still sticking on to the age old concept of nasal packing.

Biodegradable nasal packs are rejected due to its significant cost difference against other routine nasal packs. Hence, our innovative technique of using a commonly available, commercially prepared sponge (polyurethane foam) is well supported due to its efficacy in hemostasis, less mucosal trauma and less pain during pack removal.

The efficacy of sponge is as comparable to Merocel $\AA$, which is a time tested packing material which is already in use. Also the cost of sponge is less, as it is freely available in hospitals which can be autoclaved and used.

So sponge may be considered as an alternative packing material in developing countries where cost is a factor for compliance of patients for undergoing surgeries without compromising on quality.

\section{References}

1. Dubin MR, Pletcher SD. Postoperative packing after septoplasty: is it necessary? Otolaryngol Clin North Am. 2009; 42(2): 279-85

2. Rainer K. Weber. Nasal packing and stenting. GMS Curr Top Otorhinolaryngol Head Neck Surg. 2009; 8

3. Raghunathan S, Kameswaran M, Thomas JK. A prospective double blinded randomized controlled study comparing the efficacy of a novel biodegradable synthectic polyurethane foam (Nasopore) vs Standard polyvinyl acetate sponge (Merocel) as packing material after functional endoscopic sinus surgery: The first Indian experience. Clin Rhinol: Int J. 2014; 7(3): 105-11

4. Breshman M, Mehigan B, Curran A. An evaluation of merocel and series of 5000 nasal packs in patients following nasal surgery: A prospective randomized trial. Clin Otolaryngol. 2007; 32: 352-5

5. Dutta S, Mukherjee A, Saha J, Biswas G, Haldar D, Sen I, Sinha R. Modified Technique of anterior nasal packing: A comparative study report. Indian J Otolaryngol Head Neck Surg. 2012; 64 (4): $341-5$

6. von Schoenberg M, Robinson P, Ryan R. Nasal packing after routine nasal surgery - Is it justified? J Laryngol Otol. 1993; 107(10): 902-5

7. Akita S, Akino K, Imaizumi T, Tanaka K, Anraku K, Yano $\mathrm{H}$, Hirano A. A polyurethane dressing is beneficial for split thickness skin graft donor wound healing. Burns 2006; 32(4): 447-51

8. Handel N, Gutierrez J. Long term safety and efficacy of polyurethane foam-covered breast implants. Aesthet Surg J. 2006; 26(3): 265-74

9. Wheatley DJ, Raco L, Bernacca GM, Sim I, Belcher PR, Boyd JS. Polyurethane: material for the next generation of heart valve prostheses? European J Cardio thoracic Surg. 2000; 17: 440-8

10. Hesham A, Ghali A. Rapidrhino versus merocel nasal packs in septal surgery. J Laryngol Otol. 2011; 125(12): 1244-6

11. Yilmaz MS, Guven M, Elicora SS, Kaymaz R. An evaluation of biodegradable synthetic polyurethane foam in patients following septoplasty: A prospective randomized trial. Otolaryngol Head Neck Sur. 2013; 148(1): 140-4. 